\title{
O impacto do suicídio sobre a morbimortalidade da população de Itabira
}

\author{
The impact of suicide on morbidity and mortality \\ in the population of Itabira
}

Edinilsa Ramos de Souza 1

Maria Cecília de Souza Minayo ${ }^{2}$

Fátima Gonçalves Cavalcante 3

\footnotetext{
1 Centro Latino-Americano de Estudos de Violência e Saúde Jorge Careli, Departamento de Epidemiologia e Métodos Quantitativos em Saúde, ENSP, Fiocruz. Av. Brasil 4036, sala 700 , Manguinhos, 21040-361, Rio de Janeiro.

2 Claves, ENSP, Fiocruz.

${ }^{3}$ Instituto Fernandes Figueira, Fiocruz.
}

\begin{abstract}
The suicide rates in Itabira, a city, with 100,000 inhabitants, are higher than those of the Brazilian population in general. To understand this phenomenon we investigated morbidity and mortality in this population through a descriptive epidemiological study, with emphasis to external causes and specific subgroups. Suicide was studied according to the characteristics of victims and events. The period under study was 1990-2001. Mortality data were collected from the Mortality Information System (MIS) and morbidity data for the year 2000 from the Hospital Admission Authorization System (HAA). An active data search on suicide over the period 19962001 based on sex, age and occupation of the victim, month of occurrence and method used in completed and attempted suicides was conducted at the local notary's office and at the state police headquarters. Based on these data we calculated proportions, rates and mean values. The populations used for calculating the rates were extracted from the Datasus base. Results indicated an increasing tendency to suicide among men, coinciding with the economical crisis caused by the reorganization of the iron production process in this mono-industrial city. Suicide attempts were more frequent among housewives, housekeepers and students. The mostly used methods were hanging and firearms. Relevant means used in suicide attempts were nonmedicinal substances, drugs and medicaments.
\end{abstract}

Key words Morbidity and mortality, External causes, Suicide, Attempted suicide
Resumo As taxas de suicídio em Itabira, município com cerca de 100.000 habitantes, são mais elevadas do que as da população brasileira. Para entender esse fenômeno, investigou-se a morbimortalidade da população por meio de estudo epidemiológico descritivo, com ênfase nas causas externas e subgrupos específicos, destacando-se o suicídio, segundo características das vítimas e dos eventos, no período de 1990 a 2001 com base no Sistema de Informações sobre Mortalidade; e internações, por meio das Autorizações de Internações Hospitalares para 2000. Fez-se busca ativa das informações sobre suicídios no cartório e no batalhão de polícia militar locais, no período de 1996 a 2001, segundo sexo, idade e ocupação da vítima, mês de ocorrência e meio usado no suicídio consumado e nas tentativas. Calcularam-se proporções, taxas e médias referentes a esses dados. As populações usadas no cálculo das taxas foram extraídas do site do Datasus. Os resultados apontam para tendência de aumento de suicídios entre homens, coincidindo com a reestruturação produtiva que ocorreu nesta cidade monocultora da mineração de ferro. As tentativas são crescentes para donas de casa, domésticas e estudantes. Os suicídios se dão principalmente por enforcamento e armas de fogo. Nas tentativas são relevantes substâncias não-medicinais, drogas e medicamentos.

Palavras-chave Morbimortalidade, Causas externas, Suicídio, Tentativa de suicídio 


\section{Introdução}

Esta análise epidemiológica que focalizou o suicídio em Itabira fez parte de um estudo mais amplo e mais profundo sobre uma questão que hoje mobiliza os moradores do município. Boa parte dos habitantes locais verbaliza sua preocupação com um crescimento inusitado desse fenômeno, num período recente de 12 anos que coincide com uma radical reestruturação produtiva na indústria de mineração de ferro, uma monocultura, num município em que mais de $90 \%$ de sua população vive em torno dessa atividade. A pesquisa que deu origem a este texto abrangeu várias perspectivas: 1) um estudo socioantropológico a respeito da população trabalhadora e sobre os moradores, focalizando-se a reestruturação produtiva; 2 ) um estudo de autópsia psicossocial e sobre histórias de vida dos suicidas e dos que tentaram suicídio; e 3) este estudo, de cunho epidemiológico. Alguns trabalhos sob as diferentes perspectivas estudadas já foram publicados: abordagem do contexto, da população e das relações sociais de trabalho ${ }^{1}$; abordagem sociocultural e psicológica do suicídio ${ }^{2}$; explicitação da abordagem metodológica complexa ${ }^{3}$ com que o suicídio foi tratado; e uma análise-síntese denominada $\mathrm{A}$ eloqüência do gesto final ${ }^{4}$. Especificamente, na análise epidemiológica buscou-se também tratar o tema do suicídio de forma contextualizada, colocandoo no interior do conjunto da mortalidade e da morbidade geral e das causas externas. Esse olhar mais abrangente permitiu ao mesmo tempo relativizar o peso dos eventos auto-infligidos no conjunto tanto de outros problemas de saúde como no perfil da morbimortalidade. Ficou evidente que outras causas de morte por violência, como o homicídio, e por acidentes, como os que ocorreram no trânsito e os afogamentos, foram muito mais significativos em termos de magnitude ${ }^{5,6}$, no período. A elevação de ocorrência de suicídios e de tentativas, porém, foi também real, como se verá nos dados aqui descritos e analisados. O processo de reestruturação produtiva, que provocou muito desemprego, subemprego e exclusão do mercado formal de trabalho, passou a mobilizar muito o imaginário social. Segundo estudos clássicos ${ }^{7} \mathrm{e}$ atuais $^{8}$, as taxas de suicídio são mais ou menos constantes, porém costumam se elevar em momentos históricos de desestabilização e de transição social.

\section{Material e método}

\section{Sobre a mortalidade}

Os dados de mortalidade corresponderam ao período de 1990 a 2001 e foram obtidos do Sistema de Informação sobre Mortalidade (SIM) do Ministério da Saúde ${ }^{9-11}$, cuja fonte primária de informação é a Declaração de Óbito (DO). Para os dados de mortalidade referentes ao período de 1990 a 1995 foi usada a 9a revisão da Classificação Internacional de Doenças (CID-9) e para os anos de 1996 a 2001 foi considerada a 10a revisão dessa classificação.

Foram recortadas informações sobre mortalidade geral, por causas externas e por suicídio em Itabira. Para uma análise comparativa, consideraram-se dados sobre Belo Horizonte, Minas Gerais e Brasil. Calcularam-se proporções e taxas de mortalidade geral e por causas externas para as áreas e período estudados, segundo sexo e faixa etária. Todas as taxas de mortalidade foram calculadas com base na população residente fornecida no site do Datasus ${ }^{12}$.

As taxas de mortalidade por causas externas foram analisadas em conjunto e segundo subgrupos específicos (acidente de trânsito, homicídio, suicídio, quedas e outros). Para o suicídio detalharam-se informações sobre sexo, idade, escolaridade, estado civil, naturalidade e tipos de suicídio. As idades foram agrupadas nas faixas de 0 a 14; 15 a 24; 25 a 39; 40 a 59; 60 ou mais anos. A classificação das profissões seguiu o Código Brasileiro de Ocupação (CBO). O sexo, a escolaridade e o estado civil foram definidos de acordo com o CD-ROM dos Dados de Declaração de Óbito do Datasus.

Visando conhecer a subestimação apontada por vários autores ${ }^{13,14}$ e complementar os dados sobre suicídio consumado, foi realizada uma busca ativa para o período de 1996 a 2001 (anos para os quais havia dados registrados e disponíveis). Para isso, consultaram-se duas fontes de dados do município: o Cartório, cujo instrumento de coleta é a mesma DO que gera as informações do SIM; e o Boletim de Ocorrência (BO) Policial, que fica arquivado no Batalhão da Polícia Militar. Os casos incluídos foram pré-selecionados e extraídos do conjunto de ocorrências pelos próprios policiais do batalhão. Buscou-se incluir todos os casos declarados de suicídio na DO e no BO, e também as mortes com suspeita de suicídio a partir da DO, que foram confirmadas pelo BO.

Foram excluídos todos os óbitos decorrentes de causas diferentes de suicídio. Também não foram tratados os não oficialmente declarados em 
nenhuma das duas fontes investigadas e nem os caracterizados como possíveis suicídios, mas de difícil elucidação da causa básica de morte, como óbitos por afogamento. Essa exclusão se deu mesmo quando havia informação oral de se tratar de casos de morte auto-infligida ou tentativa.

\section{Sobre a morbidade}

As informações sobre morbidade por lesões e envenenamentos foram coletadas do banco de dados "Arquivos Reduzidos 2001" do Movimento de Autorização de Internação Hospitalar (AIH), do CD-ROM cedido pelo Ministério da Saúde. Consideraram-se os diagnósticos primários (a lesão que levou à internação) e secundários (a causa externa que gerou a lesão e, conseqüentemente, a internação) das causas de hospitalização, relativos a Itabira, Belo Horizonte, Minas Gerais e Brasil, no ano de 2001.

A análise identificou as cinco principais causas de internação e especificou o grupo das lesões e envenenamentos, sobretudo no que se referem às internações por tentativas de suicídio. Os dados foram estudados por sexo, idade e ocupação da vítima, sazonalidade e letalidade. Também foi analisado o universo das tentativas de suicídio a partir das AIH, comparado com dados coletados no Batalhão da Polícia Militar de Itabira.

Fez-se busca ativa com finalidade de complementar as informações referentes a tentativas de suicídio no município. Na coleta dessas informações, foram usados como fonte os dados do Batalhão da Polícia Militar do município no período de 1996 a 2001. Como tentativas foram considerados todos os casos registrados como tal no $\mathrm{BO}$ arquivado no referido batalhão. Dessas informações, foram coletadas variáveis de sexo, idades, ocupação, meio usado para perpetrar a tentativa e mês de ocorrência das tentativas de suicídio.

\section{Resultados}

\section{Análise da mortalidade geral}

O total de óbitos por todas as causas em Itabira, para o período de 1990 a 2001, foi de 6.372 óbitos (56,1\% homens e 43,9\% mulheres), com média anual de 531 óbitos. A taxa de mortalidade geral caiu 26,7\%, passando de 659,29 em 1990, para 520,19 óbitos por 100.000 habitantes em 2001. Cerca de metade dos óbitos por todas as causas, em Itabira, concentrou-se na faixa etária idosa, ou seja no grupo de 60 ou mais anos (48,1\% em 1990 e $54,3 \%$ em 2001).

Na tabela 1 observa-se que, nos anos de 1990 e 2001, doenças do aparelho circulatório, neoplasias, doenças do aparelho respiratório, causas externas e doenças endócrinas, nutricionais e metabólicas aparecem como as cinco principais causas de morte da população itabirana (excluindo-se a mortalidade por sinais e sintomas mal definidos e afecções originadas no período perinatal). Juntas, essas cinco principais causas representaram quase $70 \%$ de todos os óbitos do município no período estudado.

Tabela 1

Principais causas de mortalidade em Itabira, segundo grandes grupos de causas. Anos de 1990 e 2001.

\begin{tabular}{lcccccc}
\hline Grandes grupos de causas & \multicolumn{2}{c}{1990} & & \multicolumn{2}{c}{2001} \\
& $\mathrm{n}$ & $\%$ & & $\mathrm{n}$ & $\%$ \\
\hline Doenças do aparelho circulatório & 185 & 33,3 & $1^{\mathrm{a}}$ & 154 & 29,7 & $1^{\mathrm{a}}$ \\
Neoplasias & 59 & 10,6 & $2^{\mathrm{a}}$ & 71 & 13,7 & $2^{\mathrm{a}}$ \\
Doenças do aparelho respiratório & 57 & 10,3 & $3^{\mathrm{a}}$ & 63 & 12,1 & $3^{\mathrm{a}}$ \\
Causas externas & 53 & 9,5 & $4^{\mathrm{a}}$ & 42 & 8,1 & $4^{\mathrm{a}}$ \\
Doenças endócrinas, nutricionais e metabólicas & 37 & 6,7 & $5^{\mathrm{a}}$ & 30 & 5,8 & $5^{\mathrm{a}}$ \\
\end{tabular}

Fonte: SIM/Datasus. 
As causas externas vitimaram fatalmente 42 pessoas residentes no município, em 2001, sendo $81 \%$ óbitos de homens. À população jovem de $0 \mathrm{a}$ 24 anos corresponderam 28,6\% (n=12) dessas mortes por causas externas. Em seguida vêm as mortes por acidentes e violências dos adultos jovens de 25 a 39 anos, com $26,2 \%(n=11)$. Somados, esses dois grupos etários foram responsáveis por mais da metade (54,8\%) dos óbitos gerados por essas causas no município. Diferentemente das causas de morte anteriores que incidiram numa população mais idosa, esse grupo de eventos afetou principalmente pessoas jovens.

\section{Análise da mortalidade por causas externas}

Entre 1990 e 2001, os acidentes e violências vitimaram um total de 600 pessoas em Itabira, das quais $79,8 \%$ eram homens, o que significa uma razão de 4 homens para cada mulher e / 9,4\% de todos os óbitos da cidade. No período em estudo constatou-se uma queda nas taxas de mortalidade por essas causas, tanto na população geral como em cada um dos sexos, apesar de grande oscilação, como se observa no gráfico 1 . Na população em geral, a taxa passou de 63 para 42,1 por 100.000 habitantes, com diminuição de quase $50 \%$ no período. Foi de $56,7 \%$ a queda entre os homens e de $3,9 \%$ entre as mulheres.

No ano de 1990, a maioria das vítimas se en- contrava nas faixas etárias de 15 a 24 anos (30,6\%) e de 25 a 39 anos (38,8\%). Esse quadro se alterou no ano de 2001, com ênfase na população um pouco mais velha, ou seja nas idades de 25 a 39 anos $(26,2 \%)$ e de 40 a 59 anos $(29,6)$.

$\mathrm{Na}$ análise das causas externas, segundo subgrupos específicos (tabela 2), os acidentes de trânsito preponderaram, provocando maior número de mortes entre 1990 e 2001 em Itabira (153 vítimas). A média anual de mortes por essa causa foi de 12,7 nesses 12 anos, atingindo principalmente jovens das faixas de 15 a $24(28,10 \%)$ e adultos de 25 a 39 anos (28,75\%), do sexo masculino (76,5\%).

Depois dos acidentes de trânsito, os homicídios são o subgrupo mais relevante. Durante o período, aconteceram 126 assassinatos em Itabira, representando uma média de 10,5 ao ano. As vítimas foram, principalmente, homens $(69,8 \%)$, jovens $(20,6 \%)$, na faixa dos 15 aos 24 anos e adultos jovens (35,7\%) nas idades de 25 a 39 anos.

É importante destacar o elevado número de afogamentos (82), que se constituiu na terceira maior causa externa de morte. As vítimas desse tipo de acidente tinham, em sua maioria, de 15 a 24 anos de idade $(32,92 \%)$ ou se encontravam na faixa dos 25 aos 39 anos $(23,17 \%)$ e eram do sexo masculino $(80,5 \%)$.

Os suicídios pesaram com 64 óbitos no conjunto das causas externas, oscilando entre 4 a 8 mortes por ano, com uma média de 5,3 óbitos

\section{Gráfico 1}

Taxas ${ }^{\star}$ de mortalidade por causas externas em Itabira, segundo sexo, 1990 a 2001.

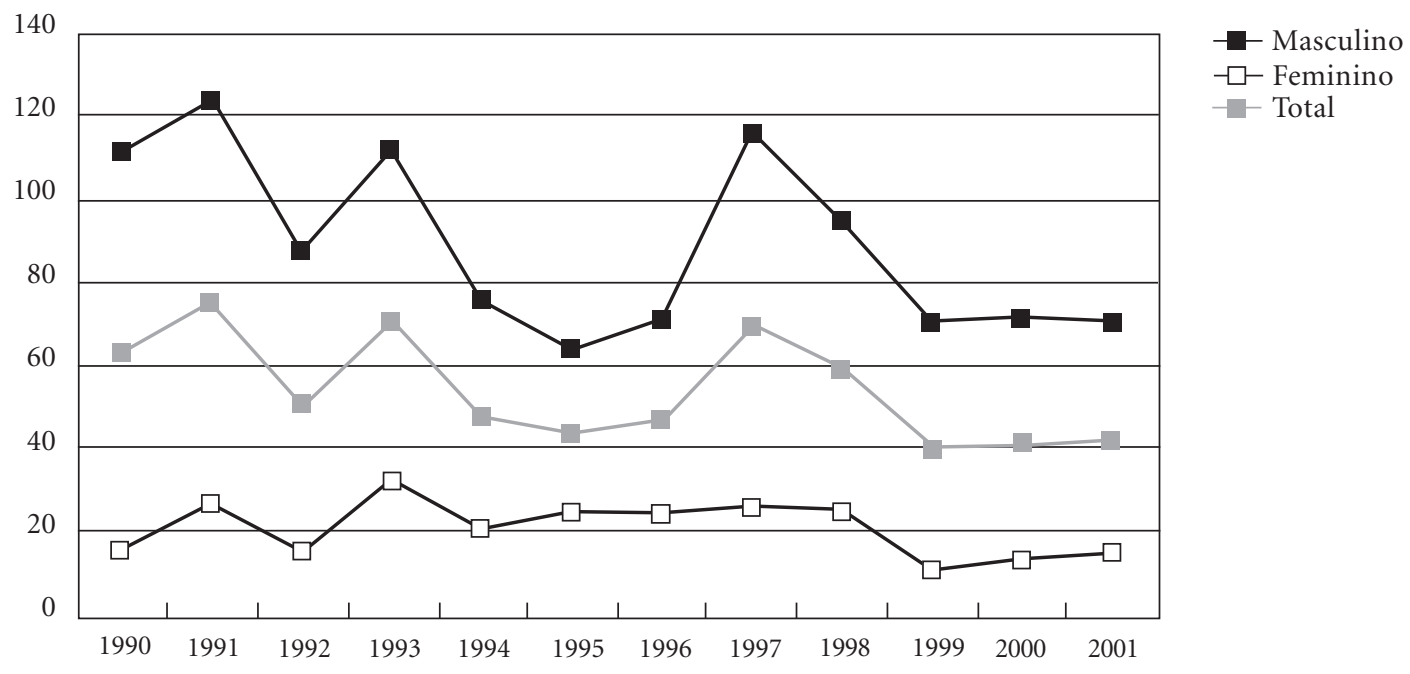

* Taxas por 100000 habitantes

Fonte: SIM / DATASUS 
anuais. Envolveram sobretudo pessoas do sexo masculino (76,6\%), em faixas etárias jovens de 15 a 24 anos $(29,7 \%)$ e de 25 a 39 anos (34,4\%).

Todas as demais causas externas totalizaram 175 óbitos, representando $29,2 \%$ e uma média de 14,6 óbitos anuais.

\section{Análise da mortalidade por suicídio}

O total de mortos por suicídio em Itabira, no período de 1990 a 2001 foi de 64, dos quais 54 homens e 10 mulheres, numa média de 5,3 casos por ano. Analisando o gráfico 2, nota-se que o ano de 1997 apresentou a maior taxa de mortalidade por essa causa, com 8,18 casos por 100.000 habitantes, enquanto em 1992 houve a menor taxa (3,43/100.000). No mesmo ano de 1997, Belo Horizonte e Minas Gerais também apresentaram as mais altas taxas, porém com valores abaixo dos observados em Itabira (5,74 e 3,79 respectivamente). Já o Brasil teve seu maior índice em 2001 $(4,46)$. Nesse último ano, foram 5 óbitos por suicídio em Itabira, 110 em Belo Horizonte, 795 em Minas Gerais e 7.682 no Brasil. Dados do cartório local apontaram leve aumento da freqüência de suicídios em Itabira durante os meses de inverno $(n=18$ ou $31,1 \%)$ e mais reduzida durante no outono $(n=12$ ou $20,4 \%)$.

Considerando-se a média das taxas trienais, para se evitar o efeito da oscilação anual, observase crescimento gradativo da mortalidade por suicídio no município, com taxas médias de 4,30 no primeiro triênio; 5,97 no segundo; 6,17 no terceiro; e 6,30 no quarto. Isso corresponde a um crescimento de $46,5 \%$ entre o primeiro e último período analisado. Esse comportamento se deve, sobretudo, a mortes masculinas cujas taxas médias foram crescentes, passando de 7,24 para 9,98, 10,50 e 11,66, respectivamente, até o final do período. Já entre as mulheres houve um incremento até o terceiro triênio e uma diminuição no último. As taxas femininas foram de 1,53, 2,13, 3,0 e 1,3 nos respectivos triênios investigados. Embora o comportamento anteriormente descrito também tenha sido observado, ainda de forma mais intensa quando se consideram dados do cartório local, o mesmo não ocorreu com as informações do Batalhão de Polícia cujas taxas médias no quarto triênio se mantiveram um pouco abaixo em relação às do terceiro triênio estudado.

Taxas crescentes de suicídio na população jovem das principais capitais brasileiras foram observados por Souza et al. ${ }^{15}$, e Santana et al. 16 também encontraram um pequeno, porém estatisticamente significativo, crescimento das taxas na população do País durante o período de 1980 a 1999. Esses autores evidenciaram para 1980 a taxa de 3,27 e para 1999, de 3,98 por 100.000 habitantes.

No período de 1996 a 2001, as informações coletadas em cartório local, seguidas pelas informações do Batalhão de Polícia Militar, evidenciaram maior número de mortes por suicídio do que os dados provenientes do SIM. Esse resultado chama a atenção, tendo em vista que tanto no SIM como no cartório a fonte primária de informação é exatamente a mesma: a declaração de óbito. Como explicar que, ao transcrever o que foi escrito na declaração de óbito para o banco de dados informatizado, tais informações se percam, gerando um sub-registro que alcançou a ordem de $117 \%$ em

\section{Tabela 2}

Distribuição da mortalidade por causas externas em Itabira, segundo número de óbitos, proporção e média anual. Período de 1990 a 2001.

\begin{tabular}{lccc}
\hline Causas externas & $\mathbf{n}$ & $\%$ & Média anual \\
\hline Acidentes de trânsito & 153 & 25,50 & 12,7 \\
Homicídios & 126 & 21,00 & 10,0 \\
Afogamentos & 82 & 13,67 & 6,8 \\
Suicídios & 64 & 10,67 & 5,3 \\
Outras causas externas & 175 & 29,17 & 14,6 \\
Total & 600 & 100,00 & 50,0 \\
\hline
\end{tabular}

Fonte: SIM/Datasus. 
Gráfico 2

Taxas $\left(^{*}\right)$ de mortalidade por suicídio em Itabira, 1990 a 2001.
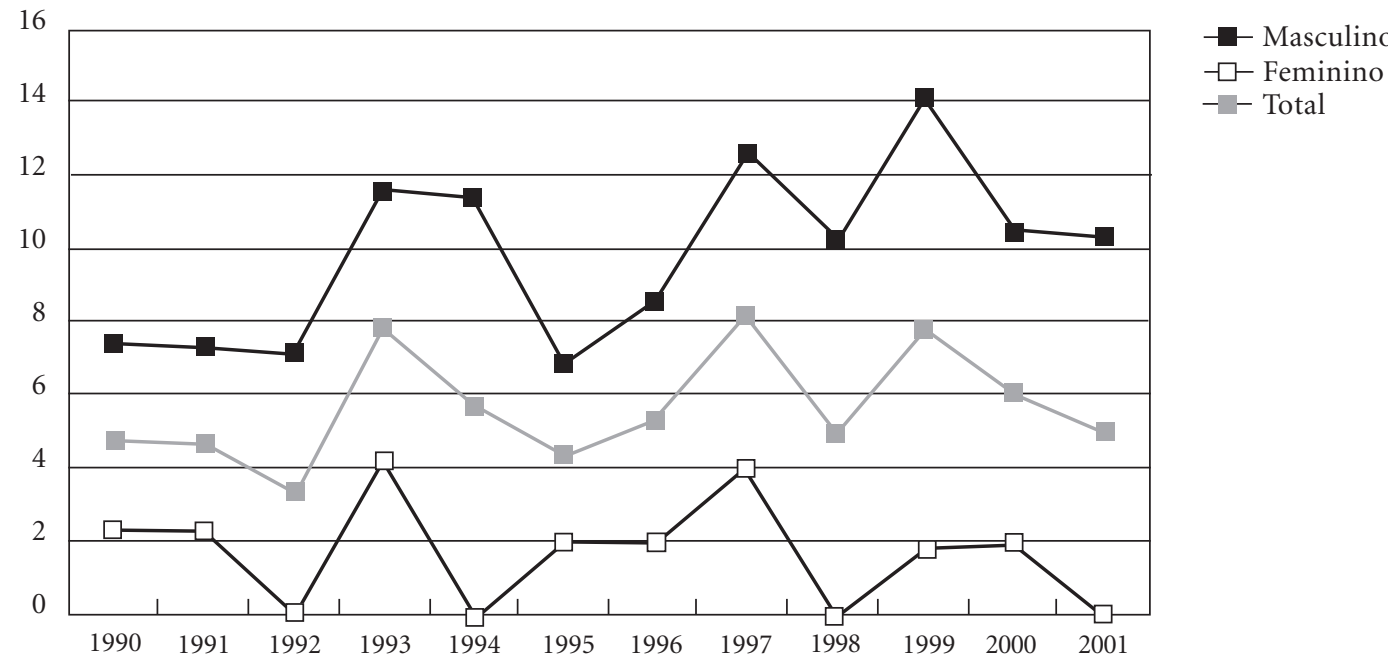

* Taxas por 100000 habitantes

Fonte: SIM / DATASUS

1996. Essa discrepância revela que há na declaração de óbito arquivada no cartório o registro de 2,2 vezes mais suicídios dos que constam no SIM. A falha se repete ao longo de todos os anos aqui comparados, reafirmando o que vem sendo reiterado por vários autores sobre a grande subestimação dos suicídios no País.

A análise dos suicídios por faixa etária e sexo indica que em 1990 os casos se concentraram, sobretudo, nas idades de 25 a 39 anos (75\%), mas também no grupo de 15 a 24 (25\%). Nesse ano foram observados 3 óbitos $(75 \%)$ masculinos por essa causa em relação a 1 (25\%) feminino. Já no ano de $2001,80 \%$ dos óbitos se referem a pessoas com 25 a 39 e 40 a 59 anos, sendo todas as mortes $(n=5)$ do sexo masculino.

Os dados referentes a Belo Horizonte, Minas Gerais e Brasil, quando analisados por sexo, se assemelham aos de Itabira, já que os homens constituem a maioria das vítimas atingidas tanto em 1990 (75,3\%, 75,5\%,74,7\%, respectivamente) quanto em $2001(80 \%, 79,1 \%$ e $79,8 \%)$. Do mesmo modo, do ponto de vista etário, também as pessoas de 25 a 39 anos e de 40 a 59 compõem a maioria dos suicidas nas diversas localidades estudadas.

De acordo com as informações do cartório local, foram 11 suicídios em 1996, dos quais 10 (90.9\%) eram de homens, e 8 em 2001, sendo 7 deles $(87,5 \%)$ também de pessoas do sexo masculi- no. Segundo essa fonte, a maioria dos suicidas foi de jovens e adultos na faixa dos 15 aos 39 anos. Os registros do cartório local mostraram-se como a melhor fonte de informação. No Batalhão de Polícia houve sub-registro, tendo sido identificados apenas 7 suicídios, em 1996 e 7 em 2001.

Em 1990, metade dos suicidas era casada e a outra metade, solteira; em 2001 o grupo era constituído de indivíduos casados (40\%), solteiros (20\%) e viúvos (20\%). Os demais encontravam-se em outras condições conjugais. A maior proporção de suicidas casados se concentrou no grupo das pessoas com mais idade, fato constatado em todas as três fontes. O número mais elevado de suicídios entre pessoas casadas em Itabira é peculiar, pois nos demais espaços sociogeográficos comparados e conforme as estatísticas internacionais revelam, a maioria das vítimas de mortes auto-infligidas se constitui de pessoas solteiras.

A análise da escolaridade das vítimas de suicídio ficou prejudicada pela elevada ausência de informação sobre essa variável. De qualquer modo, pode-se observar no ano de 1990 que metade dos suicidas possuía o $1^{\circ}$ grau e para a outra metade não havia informação. Em 2001, a escolaridade não foi esclarecida em $100 \%$ dos casos, evidenciando a piora na qualidade dos dados. Assim como em Itabira, nas demais localidades estudadas as principais vítimas de suicídios foram pessoas com apenas o $1^{\circ}$ grau de escolaridade, o que leva a pensar na restrição 
de oportunidades na vida profissional e econômico-financeira, contribuindo para a ideação, tentativas e cometimento de mortes auto-infligidas.

Nos 58 casos de suicídio registrados no cartório de Itabira, o enforcamento foi o principal meio de morte, respondendo por $55,2 \%$ dos eventos no período de 1996 a 2001. Em seguida, os instrumentos usados para a autodestruição foram armas de fogo (13,8\%); envenenamentos (13,8\%); afogamentos $(6,9 \%)$; objetos cortantes $(3,4)$; salto de lugar elevado (0,02\%); e salto/posição inerte diante de objeto móvel $(0,02 \%)$.

\section{Análise da morbidade por todas as causas}

De acordo com o diagnóstico primário do Sistema de Internação Hospitalar (SIH-SUS), houve 6.126 internações em Itabira no ano de 2000. Dessas, 2.118 foram de homens $(65,4 \%)$ e 4.008 de mulheres $(34,6 \%)$. As cinco principais causas de internação foram: gravidez, parto e puerpério (28,6\%); doenças do aparelho respiratório (12,4\%); doenças do aparelho circulatório (10,8\%); doenças do aparelho geniturinário $(8,8 \%)$ e doenças do aparelho digestivo $(8,1 \%)$.

As causas externas representaram 2,9\% de todas as internações de Itabira e situaram-se na $11^{\text {a }}$ posição, quando se considera o diagnóstico primário de lesões e envenenamentos e na 9a colocação quando o diagnóstico secundário foi adotado. Entretanto, é preciso chamar a atenção para o erro que está sendo cometido no preenchimento da ficha de diagnóstico. Quando se considera o diagnóstico principal, obtêm-se 238 internações que deveriam ser classificadas como lesões e envenenamentos. No entanto, apenas 26 hospitalizações receberam essa classificação e 212 foram notificadas como causas externas que, nesse caso, constituemse em diagnóstico secundário, estando erradamente categorizadas como diagnóstico principal. Do mesmo modo, nas notificações ocorre uma inversão de classificação quando se destaca o diagnóstico secundário. Nesse caso, foram notificadas apenas 32 internações por causas externas e 176 por lesões e envenenamentos, totalizando 208 hospitalizações, também evidenciando uma inversão no preenchimento do diagnóstico e a necessidade de treinamento das equipes de informação em saúde para essa tarefa classificatória/codificadora.

As mulheres são as maiores responsáveis pelo elevado número de internações, quando se contam problemas de gravidez e parto. Por outro lado, doenças do sistema osteomuscular, de tecido conjuntivo e causas externas são os principais problemas de saúde que levaram os homens à inter- nação. Os grupos etários que mais ocuparam leitos hospitalares foram os de 25 a 39 anos, representando $29,4 \%$ de todas as internações.

\section{Análise das internações por causas externas}

No ano de 2000, dados referentes ao diagnóstico secundário do SIH-SUS mostram que as causas externas representavam $1,6 \%$ do total de 6.126 internações. Os traumatismos $(80 \%)$ constituíram os principais motivos de hospitalização. Quedas acidentais $(40,4 \%)$ e acidentes de trânsito $(37,1 \%)$ foram as principais causas externas específicas responsáveis pelo conjunto dos traumatismos. Os homens se constituíram nas maiores vítimas $(77,7 \%)$.

A distribuição segundo faixas etárias mostra maior freqüência de internações nas idades de 15 a 24 anos $(37,3 \%)$ e de 40 aos 59 (18,1\%). Nessas idades, os traumatismos (que representaram 95,2\% e $94,6 \%$, respectivamente), foram as principais causas de hospitalização.

\section{Análise das tentativas de suicídios}

Conforme dados do SIH-SUS, quando se considera o diagnóstico secundário, ocorreram apenas duas internações por tentativa de suicídio em Itabira, no ano de 2000. Em ambas, as vítimas eram homens na faixa dos 15 aos 24 anos de idade e o traumatismo foi a lesão que gerou a necessidade de internação nos dois casos. Essas duas internações representaram apenas 2,0\% do total das 100 internações por causas externas nesse ano.

Quando se analisam os dados do Batalhão da Polícia Militar, descobrem-se 539 tentativas de suicídio no período de 1996 a 2001, dos quais 124 ocorreram em 2000. Essa discrepância pode sugerir que apenas os casos mais graves acabam levando à internação hospitalar. Boa parte dos que tentaram suicídio foi atendida nas emergências e seu caso não foi registrado nas internações que geram AIH.

Comparando-se os dados de internação por suicídio em Itabira com os do Brasil, observa-se que houve no País 9.465 internações por essa causa, representando $1,5 \%$ dos casos de causas externas. Os homens constituíram a maioria dos internados (61,1\% dos casos). Esse dado que mostra a maioria da internação de homens por tentativas de suicídio contradiz a crença de que mais mulheres provocam lesões auto-infligidas. Mas pode também estar escondendo sérios problemas de notificação comentados várias vezes no decorrer do texto. Ou ainda, pode estar ressaltando que apenas as tentativas de maior gravidade, que geralmente ocor- 
rem com homens ao empregarem dosagens e meios mais nocivos, chegam aos serviços de saúde. Tais internações se concentraram na faixa etária jovem de 15 aos 39 anos (representando 57,9\% de todas as idades). As tentativas de suicídio se deram principalmente por ingestão de substâncias não medicinais $(39,4 \%)$, traumatismos $(30,4 \%)$ e intoxicação por drogas e medicamentos (22,2\%).

Perfil semelhante foi encontrado em Minas Gerais, onde 53,6\% das 2.281 internações foram de pessoas do sexo masculino. As hospitalizações por tentativas de suicídio corresponderam, porém, a $3,1 \%$ do total das causas externas, o que se constitui em percentual superior ao encontrado em Itabira e no Brasil. A faixa etária dos 15 a 39 anos também correspondeu à maioria $(63,8 \%)$ das internações, principalmente, por ingestão de substâncias não medicinais $(41,8 \%)$, drogas e medicamentos $(32,5 \%)$ e traumatismos (18\%).

As internações por tentativas de suicídio em Belo Horizonte corresponderam a 4,0\% do total de causas externas, se assemelhando ao percentual observado em Minas. Diferenciando-se das outras áreas analisadas, as internações femininas dessa capital foram superiores, representando 60,1\% de um total de 476 casos. O total de pessoas que tentaram o suicídio se concentrou mais fortemente - do que em Minas e no Brasil - na faixa etária dos 15 aos 39 anos (74,6\%). Os principais meios usados para a tentativa do suicídio nessa capital foram a ingestão de drogas e medicamentos (51,5\%), e a intoxicação por substâncias não medicinais $(32,2 \%)$. O traumatismo correspondeu apenas a $8,2 \%$ dos casos. Isso mostra um perfil diferente do Estado e do País como um todo, onde as substâncias não medicinais estão em primeiro lugar e os traumatismos representam os meios mais comuns de tentar dar cabo à vida, assinalados nos registros de internações.

Pelo fato de as tentativas de suicídio em Itabira serem mais bem informadas quando se consideram os dados oriundos do Batalhão de Polícia, escolheu-se essa fonte para se proceder à análise. Foram re-gistradas 539 tentativas, no período de 1996 a 2001, e um crescimento de 37,4\% nas médias trienais das ocorrências. Houve em média 75,7 tentativas no triênio 1996 a 1998 e 104 no período de 1999 a 2001, evidenciando-se elevação também das taxas de tentativas como dos óbitos como já foi assinalado.

A tabela 3 mostra a distribuição das tentativas de suicídio em Itabira segundo faixa etária, no período de 1996 a 2001. Quase 65\% delas ocorreram na população jovem com menos de 30 anos de idade.

\section{Tabela 3}

Distribuição das tentativas de suicídio em Itabira, 1996 a 2001.

\begin{tabular}{lcc}
\hline Faixa etária & $\mathrm{n}$ & $\%$ \\
\hline 12 a 29 & 349 & 64,8 \\
30 a 39 & 109 & 20,2 \\
40 a 50 & 38 & 7,0 \\
51 ou mais & 7 & 1,3 \\
Sem informação & 36 & 6,7 \\
Total & 539 & 100,0
\end{tabular}

Fonte: Batalhão da Polícia Militar.

Cerca de $68,1 \%(n=367)$ dessas tentativas foram perpetradas por pessoas do sexo feminino. Esse dado está de acordo com a literatura, ao mostrar que mais mulheres tentam suicídio e mais homens efetivam sua própria autodestruição.

A análise da ocupação das pessoas que tentaram suicídio em Itabira mostra que a maioria era de domésticas (18,9\%), donas de casa (18,9\%) e estudantes $(18,4 \%)$. Juntas, essas ocupações constituíram um total de 56,2\%. Essas principais atividades são condizentes com o fato de que a maioria das tentativas seja executada por mulheres.

\section{Conclusões}

Este estudo, como parte de uma pesquisa mais complexa, evidenciou o lugar que o suicídio ocupa na magnitude da mortalidade geral e da mortalidade por causas externas em Itabira. Focalizando apenas a categoria causas externas, observou-se que o suicídio ocupou nesses 12 anos, o quarto lugar. Nos primeiros lugares estão as mortes no trânsito, os homicídios e os afogamentos. No entanto, no imaginário social são os suicídios que mais preocupam e provocam angústia na população.

Especificamente sobre o suicídio, objeto primeiro da investigação, as evidências mostraram que do ponto de vista da sua magnitude, ele não se constitui na questão mais relevante. Isso permitiu relativizar e ao mesmo tempo articular informações, reflexões e propostas locais, sobretudo para o setor saúde. Propiciou também a oportunidade de se analisar a significância qualitativa dos eventos de morte e morbidade auto-infligidos como fenômenos profundamente mobilizadores das energias sociais. 
Ressaltou-se, por outro lado que, embora no interior das causas externas o suicídio ocupe o quarto lugar em taxas de mortes por acidentes e violência, há uma real tendência de crescimento das taxas, tanto das mortes como das tentativas. Demonstrou-se também que o perfil dos suicidas se diferencia dos que tentam. Para a mortalidade, a maioria se compõe de homens entre 25 a 39 e de 40 a 59 anos, casados, que usaram o enforcamento e a arma de fogo como os principais meios para perpetrar sua própria morte. Mais mulheres que homens tentaram se matar, em sua maioria, domésticas, donas de casa e estudantes (embora isso tenha sido evidenciado pelos dados da Polícia Militar e não do SIM). Mais de 50\% delas usaram substâncias não medicinais, drogas e medicamentos neste intento.

O estudo síntese 4 mostrou que o desencanto com as perspectivas de vida atuais e de projetos futuros, os abusos pessoais e familiares de álcool e doenças mentais são problemas que têm forte impacto no suicídio. E no caso das tentativas, o patriarcalismo, a vida muito fechada em casa e sem apoio de redes sociais, a violência intrafamiliar e a vitimização por abusos físicos, psicológicos, negligências e violência sexual, muitas vezes ocorrendo de forma associada, têm relevância, sobretudo no caso das mulheres.

Em relação aos dados, ficou evidenciada a subnotificação pelos bancos do setor saúde. A melhor fonte de informações para análise das mortes são os registros do Cartório local e, para as tentativas, o Batalhão de Polícia Militar. O SIM evidencia subregistro dos óbitos e as AIH apresentam problemas na classificação dos diagnósticos primário e secundário. Esses problemas apontam para a necessidade de melhor preparação dos profissionais para diagnosticar, notificar e codificar a causa básica de morte por violência e acidentes em geral, sobretudo para os eventos de suicídio. Nas tentativas há muitos problemas de preenchimento do prontuário médico-hospitalar. Há desconhecimento sobre dados referentes ao atendimento nas emergências, o que sugere a necessidade de implantação de normas e rotinas para a notificação, se não de todos os acidentes e violências, pelo menos daqueles que são um problema de saúde pública no município.

$\mathrm{Na}$ finalização da pesquisa que deu origem a este texto e a outros citados na introdução, houve a oportunidade de discutir com os gestores da cidade todos os dados referentes aos problemas de saúde, enfatizando-se o impacto da violência e dos acidentes. Essa relevância foi consolidada sob vários aspectos: do contexto socioeconômico, dos impactos da atual reestruturação produtiva na vida dos trabalhadores e das suas famílias, das tradições culturais muito marcadas pelo patriarcalismo, das magnitudes, das relações e das subjetividades e, sobretudo, do papel das instituições locais, principalmente do setor saúde. Nesse último caso, além de se debater o enfoque da promoção, foi tratada a necessidade de preparar melhor os serviços para atender as vítimas dos eventos violentos e para produzir informações bem notificadas e fidedignas.

Ressaltou-se ainda a necessidade de se desencadear discussão acerca de programas, tratamento e prevenção para os grupos mais vulneráveis aos suicídios, que podem ser detectados e acompanhados pelos programas de Saúde da Família, mas necessitam também de atenção profissional especializada.

Por fim, buscou-se aqui evidenciar que, a partir de um caso e de uma pergunta específica, podese analisar em profundidade situações que têm especificidade e também podem ser generalizadas. Ao compreendê-las, podemos avançar no conhecimento e colaborar para aumentar a qualidade de vida e, sobretudo, da gestão do setor saúde.

\section{Colaboradores}

ER Souza participou da concepção teórica e foi responsável pela revisão final do texto. MCS Minayo participou da revisão final do texto. FG Cavalcante foi responsável pela coordenação da coleta de dados e colaborou com a revisão final do texto. 


\section{Referências}

1. Minayo MCS. De ferro e flexíveis: marcas do estado empresário e da privatização na subjetividade operária. Rio de Janeiro: Garamond; 2004.

2. Cavalcante FG, Minayo MCS. Organizadores psíquicos e suicídio: retratos de uma autópsia psicossocial. In: Prado MCA, coordenadora. O mosaico da violência: a perversão na vida cotidiana. São Paulo: Vetor; 2004. p. 371-431.

3. Minayo MCS, Cavalcante FG, Souza ER. Proposta metodológica para abordagem de suicídio como fenômeno complexo. Cad Saúde Pública 2006; 22(8):1587-96.

4. Minayo MCS, Cavalcante FG, Souza ER. A eloqüência do gesto final: suicídio em Itabira. Rio de Janeiro: Claves/Fiocruz; 2004. Relatório de pesquisa.

5. Mello-Jorge MHP, Gotlieb SLD. As condições de saúde no Brasil. Rio de Janeiro: Ed. Fiocruz; 2000.

6. Souza ER. Homicídio: o grande vilão da saúde pública na década de 80. Cad Saúde Pública 1994; 10(Supl. 1):135-45.

7. Durkheim E. O suicídio. São Paulo: Abril; 1980. (Coleção Os Pensadores).

8. Ostamo A, Lahelma E, Lönnqvist J. Tansitions of employement status among suicide attempters during a severe economic recession. Soc Sci Med 2001; 52(11):1741-50

9. Brasil. Ministério da Saúde. Banco de dados do Sistema de Informação sobre Mortalidade: 1979 a 1998 - dados de Declaração de Óbito [CD-ROM]. Brasília: MS; 2000

10. Brasil. Ministério da Saúde. Banco de dados do Sistema de Informação sobre Mortalidade: 1996 a 2000 [CD-ROM]. Brasília: MS; 2002
11. Brasil. Ministério da Saúde. Banco de dados do Sistema de Informação sobre Mortalidade: 2001 [CD-ROM]. Brasília: Ministério da Saúde; 2003.

12. Brasil. Ministério da Saúde. Banco de dados do Sistema Único de Saúde. 2006 Maio [acessado 2006 maio 10]. Disponível em: http://www.datasus.gov.br

13. Souza ER. Violência velada e revelada: estudo epidemiológico da mortalidade por causas externas em Duque de Caxias [dissertação]. Rio de Janeiro: Escola Nacional de Saúde Pública, Fundação Oswaldo Cruz; 1991.

14. Mello-Jorge MHP. Investigação sobre a mortalidade por acidentes e violências na infância [tese]. São Paulo: Faculdade de Saúde Pública; 1988.

15. Souza ER, Minayo MCS, Malaquias JV. Suicide among young people in selected Brazilian State Capitals. Cad Saúde Pública 2002; 18(3):673-83.

16. Santana FS, Souza ER, Minayo MCS, Malaquias JV, Reis AC. Evolução temporal da mortalidade por suicídio no Brasil, 1980 a 1999. Boletim Claves/Cenepi [periódico na Internet] 2002 dez. Disponível em: http://www.claves.fiocruz.br/boletim\%206.pdf

Artigo apresentado em 25/02/2006

Aprovado em 9/03/2006

Versão final apresentada em 25/04/2006 